\title{
Impact of a submarine on the seabed
}

\author{
J. G. Pelaez ${ }^{1}$, G. R. Valiente ${ }^{1}$ \& J. J. Reijmers ${ }^{2}$ \\ ${ }^{I}$ Navantia, Spain \\ ${ }^{2}$ Nevesbu, The Netherlands
}

\begin{abstract}
Under certain circumstances it may be desired to place a submarine on the seabed. In this static situation it is possible to shut down vital systems required for manoeuvring, hence avoiding the radiation of sound.

This bottoming should be considered as a controlled collision; however this operation is not without risk. First touch down may be anticipated, but hydrodynamic aspects will be influenced by the seabed. A change in trim and speed will result in an impact velocity of vulnerable structures, other than the reinforced area for initial touch down. The paper focuses on the impact of the aft rudder with the seabed following from a nose down first touch down.

Depending on forward trim and downward velocity the rotation of the vessel and velocity of the aft rudder is analysed.

Structural analyses are carried out, including soil mechanics to assess the property of the seabed.

Nonlinear material behaviour, including strain rate effects is taken into account. Although the connotation collision suggests otherwise, bottoming shall be considered as a normal operation. This implies that the impact of the aft rudder on the seabed shall not result in a permanent set.

With the explicit code LS Dyna the response on several downward velocities and trim angles is calculated. The criterion of no plastic deformation produces an operational window for trim and velocity to approach the seabed.

Keywords: submarine, impact, seabed.
\end{abstract}

\section{Introduction}

Although bottoming of a submarine contains a risk of damage it may be desired under certain circumstances. Relevant scenarios for bottoming are [1]: 
- Launching Special Operation Forces by lock-out/lock-in. Carrying out this operation from a platform that may show unexpected depth excursions puts the divers at high risk.

- Intelligence gathering of enemy harbours. This covert operation requires a minimum probability of detection and this is achieved by shutting down as many systems as possible.

- Traditional "cover and wait" tactics in Anti-Submarine Warfare. In this case too noise producing systems, e.g. manoeuvring equipment, will be shut down.

- Submarine escape and rescue training. An example of these exercises is given by Bold Monarch.

These operations have in common that the collision is planned and the impact is completely under control. Nevertheless it requires skill and the behaviour of the vessel shall be well known to the commanding officer. The following study offers an operational envelop containing the allowable approach conditions in order to prevent damage at impact.

\section{Interaction with the seabed}

According to Archimedes' law the submarine is hovering when the weight of the submarine equals the displacement. Increasing the weight by pumping in trim water disturbs this equilibrium and the submarine moves towards the seabed. The mass of the submarine is increased by the mass of the entrained water and without influence of the seabed the cylinder of the hull carries an equal amount of entrained water. Added mass is presented by figure 1 for a floating cylinder.

Only the lower part is submerged and without influence of the seabed $(c>>R$ and $\gamma=1$ ) the submerged area of the cylinder, $1 / 2 \pi . R^{2}$, carries an equal area of entrained water.

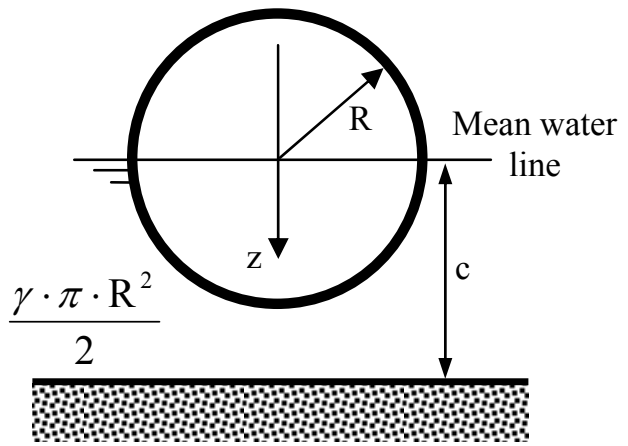

\begin{tabular}{c|c}
$\frac{\mathrm{c}}{\mathrm{R}}$ & $\gamma$ \\
\hline 1.2 & 1.83 \\
1.5 & 1.45 \\
2.0 & 1.22 \\
3.0 & 1.09 \\
5.0 & 1.03 \\
$:$ & 1.00
\end{tabular}

Figure 1: $\quad$ Added mass for cylinders with wall effects [2].

Fully submerged the upper half also carries this amount of entrained water. With influence of the seabed $(\mathrm{c} / \mathrm{R}<5)$ the factor $\gamma$ increases and the lower part of the cylinder carries more mass, which affects the equation of motion. With a 
large distance to the seabed the standard displacement, $\Delta$ with an equal added mass, $M_{\text {add }}$ gives an equation of motion:

$$
\mathrm{M}_{\mathrm{o}} \cdot \ddot{\mathrm{z}}+\alpha \cdot \mathrm{M}_{\mathrm{o}} \cdot \dot{\mathrm{z}}=\mathrm{F}_{\text {grav }}
$$

In eqn (1) the total mass is given by: $\mathrm{M}_{\mathrm{o}}=\Delta+\mathrm{M}_{\mathrm{add}}+1.8$ [ton] trim water. Hydrodynamic damping is considered to be mass related (absolute damping) given by the factor, $\alpha$. With an initial velocity equal to zero the submarine is picking up speed in vertical (z-) direction and the final constant velocity is governed by the damping coefficient, $\alpha$.

The right hand side of the equation shows the force driving the submarine to the seabed. It shall be realized that this force originates from the additional amount of trim water only. Application of standard gravity would neglect the buoyancy and hence violate Archimedes' law. Therefore the gravity acceleration will be adjusted to:

$$
\mathrm{g}_{\mathrm{adj}}=\frac{\mathrm{F}_{\text {grav }}}{\mathrm{M}_{\mathrm{o}}}
$$

The seabed influence affects the mass and based on factor, $\gamma$ in figure 1 the mass is expressed by:

$$
\mathrm{M}(\mathrm{z})=\mu(\mathrm{z}) \cdot \mathrm{M}_{\mathrm{o}}
$$

Figure 2 shows the curve based on the data from Blevins [2] and the hyperbolic fit for $\mu(\mathrm{z})$. In the following analyses the $\mathrm{z}$-coordinate runs from $\mathrm{z}=0$ $-16.2[\mathrm{~m}]$ or $\mu(\mathrm{z}) \approx 1.0$ to:

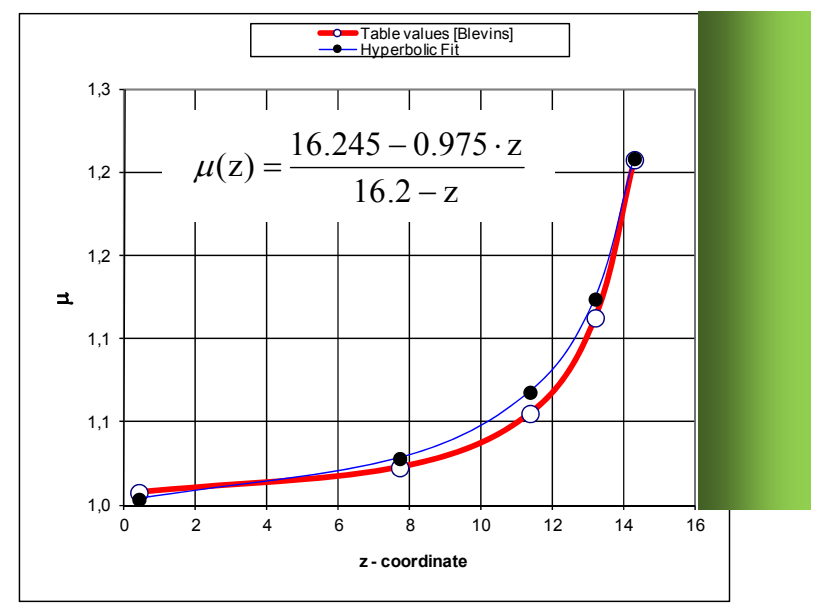

Figure 2: $\quad$ Factor for seabed influence. 
Substitution of the varying mass in eqn (3) into the equation of motion eqn (1) gives:

$$
\begin{gathered}
\mu(\mathrm{z}) \cdot \mathrm{M}_{\mathrm{o}}(\ddot{\mathrm{z}}+\alpha \cdot \dot{\mathrm{z}})=\mathrm{F}_{\text {grav }} \text { or: } \\
\mathrm{M}_{\mathrm{o}} \cdot \ddot{\mathrm{z}}+\alpha \cdot \mathrm{M}_{\mathrm{o}} \cdot \dot{\mathrm{z}}=\frac{\mathrm{F}_{\text {grav }}}{\mu(\mathrm{z})}
\end{gathered}
$$

The right hand side of the equation represents a constant force $\left(\mathrm{F}_{\text {grav }}\right)$ and a force depending on displacement. The latter part defines a nonlinear spring and this leads to:

$$
\mathrm{M}_{\mathrm{o}} \cdot \ddot{\mathrm{z}}+\alpha \cdot \mathrm{M}_{\mathrm{o}} \cdot \dot{\mathrm{z}}+\mathrm{K}(\mathrm{z}) \cdot \mathrm{z}=\mathrm{F}_{\text {grav }}
$$

The motion presented by eqn (5) is analysed by a simple cylinder with the proper mass and suspended by nonlinear springs, see figure 3 . The code applied is LS Dyna embedded in ANSYS.

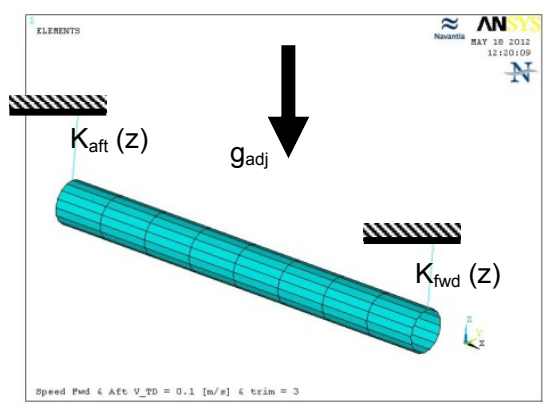

(a) Simple model

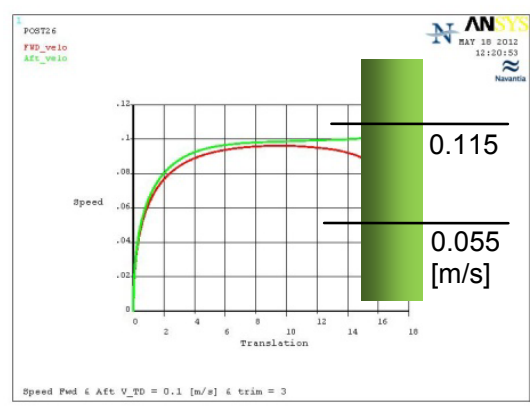

(b) Speed versus translation

Figure 3: $\quad$ Simple model for motion analysis.

This model is applied for motion analysis addressing a range of speeds $(0.05$ $-0.5[\mathrm{~m} / \mathrm{s}])$ and forward trims $\left(1^{\circ}-3^{\circ}\right)$. The procedure is nose down first to control the impact. The aft ship comprises vulnerable parts and these should not be subjected to first impact.

Trim requires adjustment of the spring stiffness and this is achieved by simply shifting the load deflection curve of the aft spring over the trim distance.

Figure 3(b) shows the speed for an intended touch down at $0.1[\mathrm{~m} / \mathrm{s}]$ in combination with a forward trim of $3^{\circ}$. This speed is realized by adjusting the factor for mass related damping, $\alpha$. The downward speed increases from zero to the intended $0.1[\mathrm{~m} / \mathrm{s}]$, but the presence of the seabed decreases the speed of the nose. This results in rotation of the vessel and the velocity of the aft ship increases. Note that there is no actual seabed. The nonlinear springs describe the influence of the seabed and touch down is defined by translation over a distance of $16.2[\mathrm{~m}]$ only. 


\section{Seabed properties}

The seabed is modelled following Terzaghi's law [3]:

$$
\varepsilon=\frac{1}{\mathrm{C}_{10}} \log \frac{\sigma^{\prime}+\Delta \sigma^{\prime}}{\sigma^{\prime}}
$$

This logarithmic constitutive equation shows a singularity for the initial effective stress, $\sigma^{\prime}=0$. Therefore this stress is taken $z=0.1[\mathrm{~m}]$ into the seabed. Assuming a soil density, $\rho_{\text {soil }}=1325\left[\mathrm{~kg} / \mathrm{m}^{3}\right]$ the initial effective stress amounts to: $\sigma^{\prime}=\rho_{\text {soil }} \cdot g \cdot z=1300\left[\mathrm{~N} / \mathrm{m}^{2}\right]$.

The actual stress in the seabed due to compression is given by: $\sigma=\sigma^{\prime}+\Delta \sigma^{\prime}$ and the coefficient $\mathrm{C}_{10}$ varies for the soil properties [3]:

For clay: 5-100

For sand: 20-200

It will be clear that touch down at solid rock will produce a much more severe impact, but the condition of the seabed for intended bottoming operation will be carefully monitored. The following analyses are based on the highest value for sand, $\mathrm{C}_{10}=200$ and this produces a seabed behaviour:

$$
\varepsilon=\frac{1}{200} \log \frac{\sigma}{1300}
$$

Following this constitutive equation the seabed is modelled by nonlinear springs, see figure 4 . These springs are covered by a surface of shell elements. These elements are rather stiff with a modulus of elasticity in the range of stone. This property is merely chosen to distribute the impact fairly over the nonlinear springs. The impact pressure versus compression induced by a falling cylinder (see figure 4(a)) is presented in figure 4(b). The LS Dyna result is presented together with the analytical solution given in eqn (7). The results match very well.

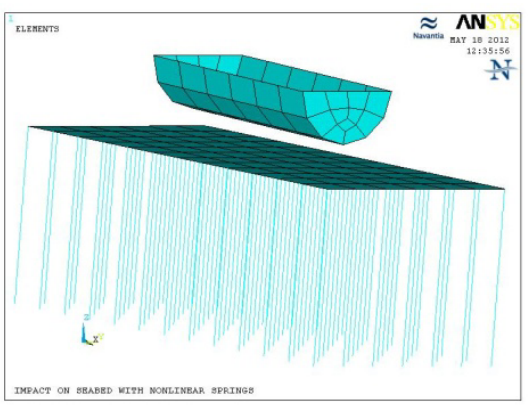

(a) Seabed model

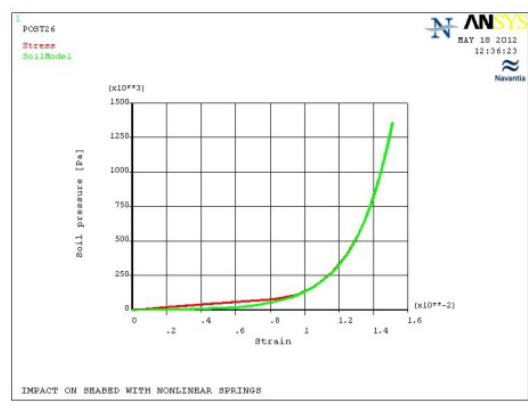

(b) pressure versus strain

Figure 4: $\quad$ Seabed behaviour according to Terzaghi [3]. 


\section{Material properties of the submarine structure}

The analysis focuses on the vulnerable aft part of the vessel, in particular the lower rudder. This is a steel structure with a yield stress, $\sigma_{\text {yield }}=355\left[\mathrm{~N} / \mathrm{mm}^{2}\right]$. The main criterion regarding bottoming is that no permanent set is allowed and this means that the material response shall stay within the elastic range. In order to clearly define the elastic range plasticity must be indicated too. Therefore a test curve of the material is used and with a piecewise linear plasticity model, available within LS Dyna, the tensile test is simulated. The actual test curve and simulation are displayed in figure 5 .

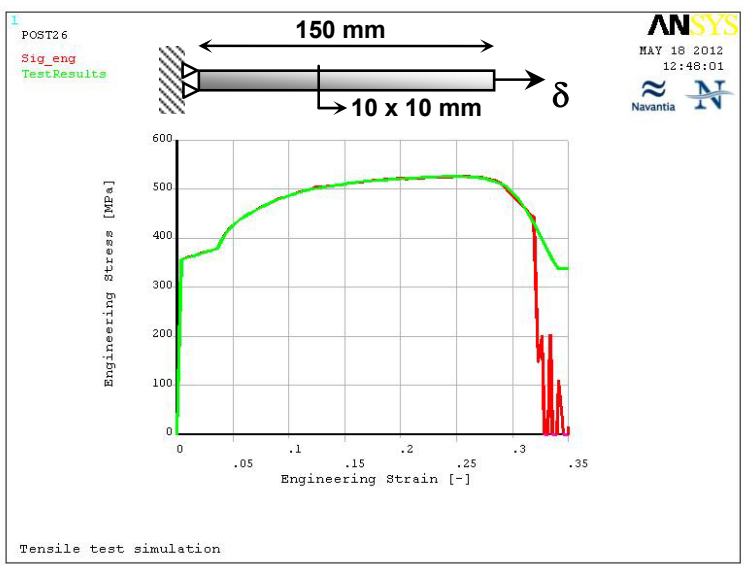

Figure 5: $\quad$ Tensile test simulation FeE355.

The simulation of the tensile test comprises a strain up to $35 \%$ realized in 1 [s]. This means quasi-static behaviour and dynamic effects, i.e. inertia forces can be neglected. During bottoming the strain rate may be much higher and this affects the yield stress of the material. The ANSYS / LS Dyna program offers the Cowper-Symonds model to incorporate the strain rate effect [4]:

$$
\sigma_{\text {yield }}(\text { dyn })=\sigma_{\text {yield }}(\text { stat }) \cdot\left\{1+\left(\frac{\dot{\varepsilon}}{\mathrm{C}}\right)^{\frac{1}{\mathrm{P}}}\right\}
$$

For carbon steel the suggested parameter values are $\mathrm{C}=40$ and $\mathrm{P}=5$

With respect to blast resistance several tests are prepared by the Liverpool University for HSE [5]. These tests consider thin stainless steel plates (AISI $316 \mathrm{~L}$ ) and for several panels the coefficients $\mathrm{C}$ and $\mathrm{P}$ are established. Eqn (8) is presented in figure 6 for the coefficients following from [4] and [5]. It shall be noted that the suggestion made in the FE guidance [4] results in a much higher yield stress than following from the tests [5]. An alternative is given by the guidance on protection against blast [6]. This formulation is presented by eqn (9) 
Different C \& P values

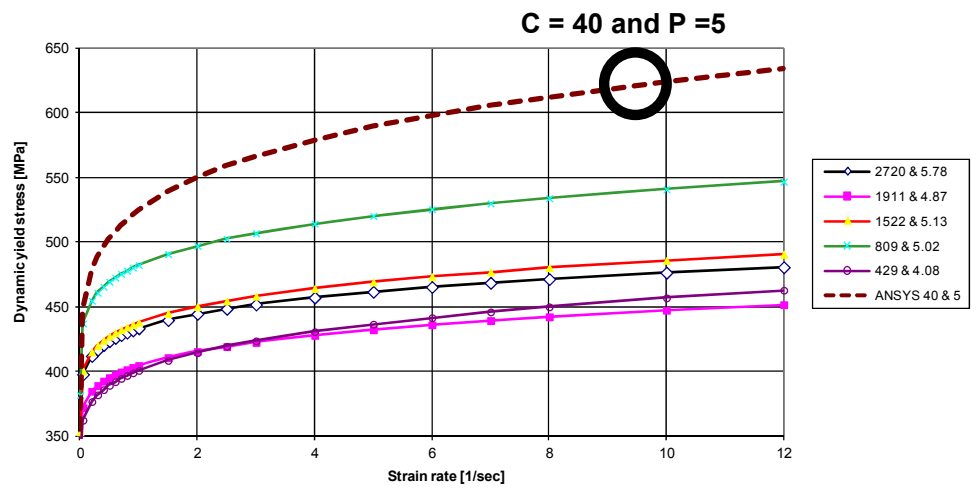

Figure 6: Strain rate effect based on Cowper-Symonds.

and the coefficients acting on the strain rate are similar to the FE guidance [4]. However the modified formulation brings the ratio dynamic/static yield stress within the test results from HSE [5], see figure 7.

$$
\sigma_{\text {yield }}(\text { dyn })=\sigma_{\text {yield }}(\text { stat })-25+210 \cdot\left(\frac{\dot{\varepsilon}}{40.4}\right)^{\frac{1}{5}}
$$

Since the ANSYS/LS Dyna program offers also the possibility to enter the ratio dynamic/static yield stress for a range of strain rates the formulation given in eqn (9) will be applied.

Different C \& P values

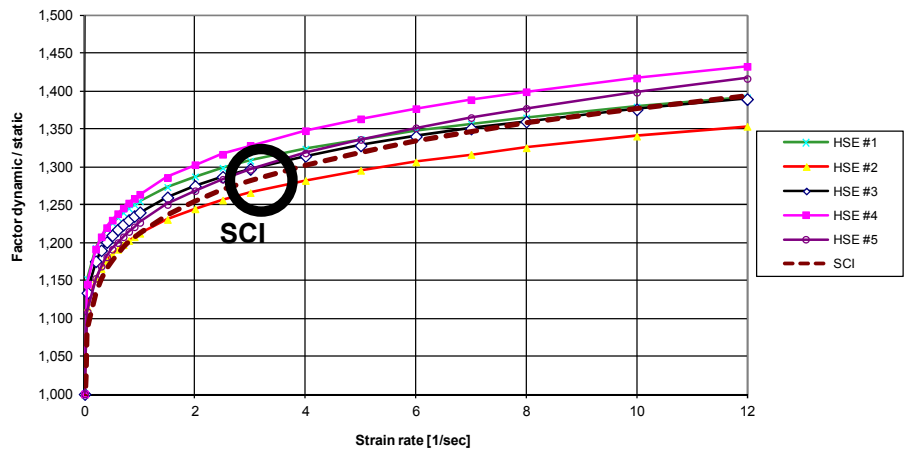

Figure 7: Ratio (dynamic/static) yield stress.

The simulation model consists of a strip with a length of $150[\mathrm{~mm}]$ and a cross section $10 \times 10[\mathrm{~mm}]$, see figure 5 . In order to check the strain rate effect 
an elongation, $\delta=30[\mathrm{~mm}]$ is applied in 40 [ms]. This gives an engineering strain, $\varepsilon_{\text {eng }}=\frac{30}{150}=0.2$ and a strain rate $\dot{\varepsilon}=\frac{0.2}{0.04}=5$. According to figure 7 this gives an increase of yield stress by 32\%: $\sigma_{\text {yield }}(\mathrm{dyn})=1.32 \cdot \sigma_{\text {yield }}($ stat $)=$ $469\left[\mathrm{~N} / \mathrm{mm}^{2}\right]$. The simulation in LS Dyna shows a dynamic yield stress, $\sigma_{\text {yield }}($ dyn $)=483\left[\mathrm{~N} / \mathrm{mm}^{2}\right]$, so only $3 \%$ higher.

This material model is applied to the aft structure of the submarine.

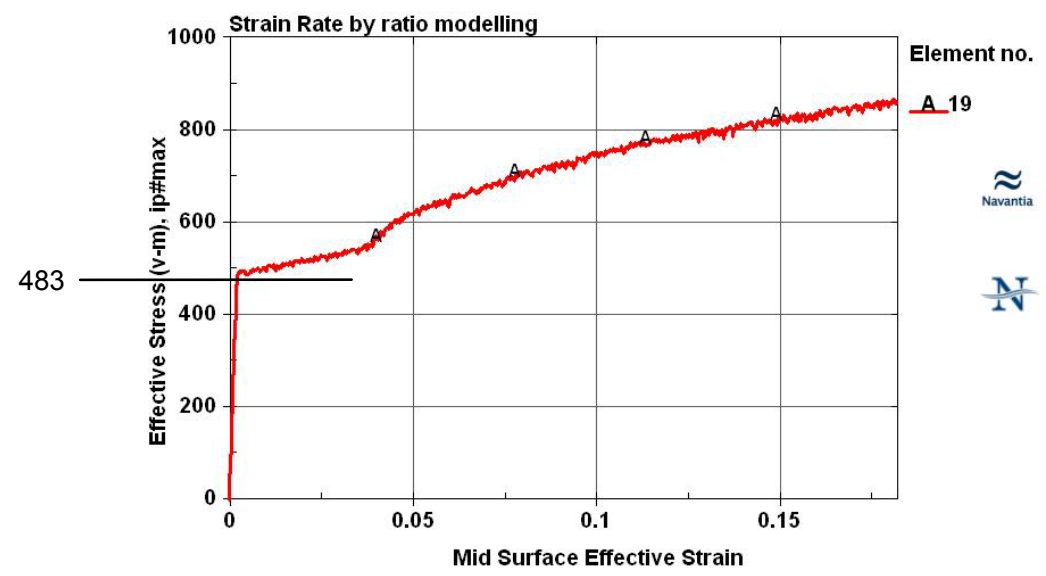

Figure 8: $\quad$ Tensile curve presenting true stress-true strain.

\section{Impact analysis}

The motion analysis is split in two phases. First the hydrostatic equilibrium is disturbed by taking in 1.8 [ton] trim water. The vessel starts to move and an absolute (or alpha) damping is set to reach the desired terminal velocity. The motion starts at $16.2[\mathrm{~m}]$ from the seabed with an increasing influence. There is no physical contact with the seabed, but the speed and rotation is considered after a translation of 16.2 [m]. This motion is analysed in section 2 and the result is input for the actual impact. The intended speed is $0.1[\mathrm{~m} / \mathrm{s}]$ with a nose down trim of $3^{\circ}$. After a translation of $16.2[\mathrm{~m}]$ the seabed slows down the nose, inducing a rotation. This implies that the trim decreases from $3^{\circ}$ to $2.15^{\circ}$ and the aft ship is picking up speed to $0.115[\mathrm{~m} / \mathrm{s}]$, so $15 \%$ more than intended. These values are used as initial conditions for impact and the FE model for the explicit analysis is displayed in figure 9. The trim is applied by tilting the seabed and for reasons of simplicity the angular velocity is accounted for by using the increased velocity on both forward and aft ship. The analysis starts with a nose clearance of $50[\mathrm{~cm}]$ and figure 10 shows the graphical presentation of touch down. Due to gravity the speed increases a bit further and after 4 [s] the nose touches the seabed. The soil is compressed, pushes the nose back and this results in a rotation of the vessel. 


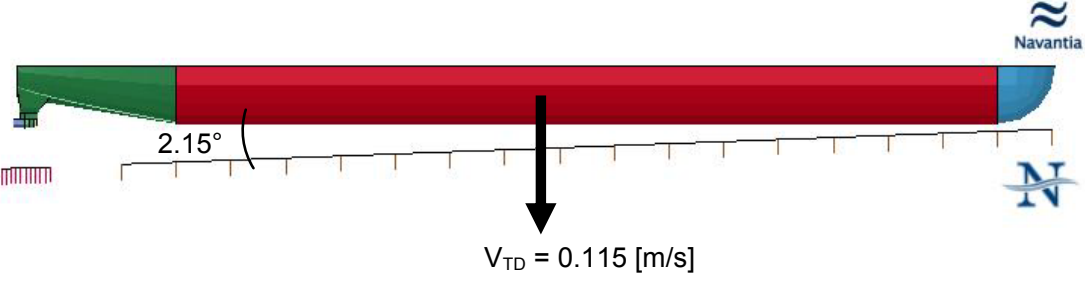

$\underline{z} \mathbf{x}$

Figure 9: $\quad$ Model for explicit analysis.

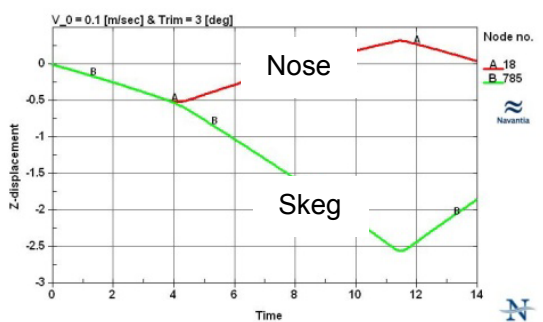

(a) Translation

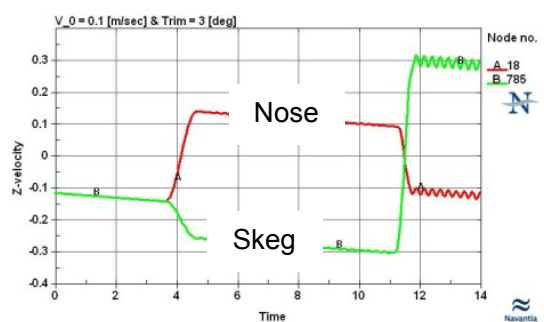

(b) Velocity

Figure 10: Graphical presentation of contact.

After 11-12 [s] the skeg touches the seabed, but in the meantime the aft ship shows an increase of the velocity up to $0.3[\mathrm{~m} / \mathrm{s}]$, see figure $10(\mathrm{~b})$.

Figure 11 shows the stress levels in the skeg and the peak stress amounts to $\sigma_{\mathrm{vM}}=387\left[\mathrm{~N} / \mathrm{mm}^{2}\right]$. This peak occurs in the skeg plating and in shipbuilding practice lateral loaded shell plates, under normal operational conditions, show stresses in excess of yield (Reijmers [7]). The stress in the shell plate exceeds the

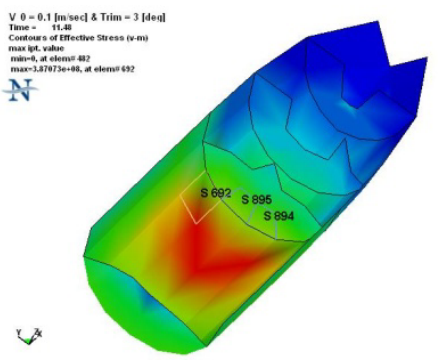

(a) Contour plot von Mises stress

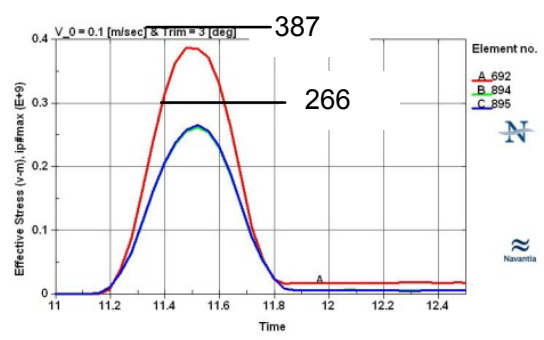

(b) von Mises stress over time

Figure 11: Stress results. 
static yield stress by not more than $9 \%$ and therefore these plate stresses are allowable. The web frames in the skeg show stress well below static yield and therefore it can be concluded that from an operational point of view bottoming with a downward speed of $0.1[\mathrm{~m} / \mathrm{s}]$ and $3^{\circ}$ forward trim is allowable.

An additional analysis is presented for a downward speed of $0.3[\mathrm{~m} / \mathrm{s}]$ and $3^{\circ}$ forward trim. The motion analysis is not presented here, but the seabed influence decreases the speed to $0.235[\mathrm{~m} / \mathrm{s}]$ and the trim from $3^{\circ}$ to $2.43^{\circ}$. The impact analysis starts with a clearance of $0.5[\mathrm{~m}]$ and this distance is bridged in around 2 [s]. The nose bounces back and the aft ship is picking up speed up to 0.47 $[\mathrm{m} / \mathrm{s}]$. The skeg touches down after $7.3[\mathrm{~s}]$, see figure $12(\mathrm{~b})$.

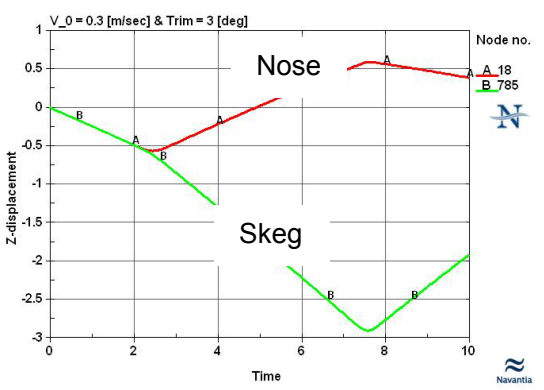

(a) Translation

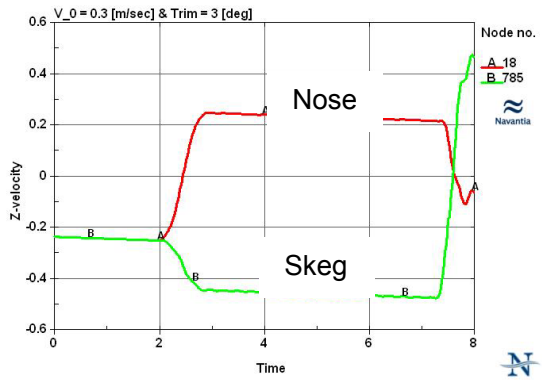

(b) Velocity

Figure 12: Contact at higher speed, $0.3[\mathrm{~m} / \mathrm{s}]$.

The stress in the skeg is displayed in figure 13 and the web frame shows a von Mises stress in excess of yield. The stress peak is cut off at $390\left[\mathrm{~N} / \mathrm{mm}^{2}\right]$ indicating a yield plateau and the increase of yield from 355 to $390\left[\mathrm{~N} / \mathrm{mm}^{2}\right]$ shows the strain rate effect. Obviously these initial conditions are intolerable from an operational point of view.

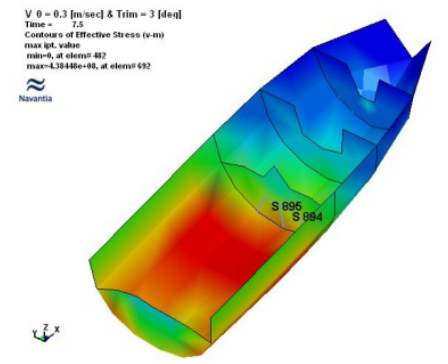

(a) Contour plot von Mises stress

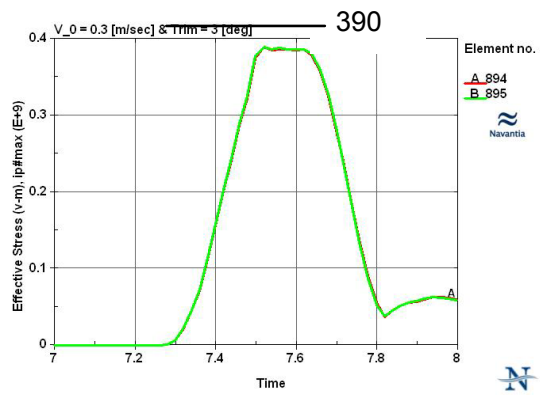

(b) von Mises stress over time

Figure 13: Stress result at higher speed, $0.3[\mathrm{~m} / \mathrm{s}]$. 


\section{Operational envelope}

As safety at sea in the maritime environment is a critical issue, extensive work has been carried out to develop the theory of ship collisions and grounding, for example at the Technical University of Denmark [8, 9], and numerical simulations are increasingly being performed [10]. Germanischer Lloyd was the first Classification Society (2004) which introduced non-compulsory rules concerning strengthening against collisions [11]). But all this work has been done to analyse the potential extent of damage and strength of the structure during these accidents or emergency events, and therefore all of them were focused on penetration/rupture of the bottom/side structure.

As explained before, bottoming of a submarine is not an accident but an occasional and tactically trained operation. This is the reason why the structural criterion should range from normal operational load to eventual/test loads. Recently developed BV Naval Submarines Rules [12] define stress safety factors for normal operational loads and eventual loads as 1.5 and 1.2 referred to the material static yield limit. At the same time, safety factor for loads due to underwater explosions is normally taken as 1.0 but considering the dynamic yield limit of the material.

Knowing that, it seems reasonable to consider a safety factor between 1.0 and 1.2 depending on the bottoming operation frequency. One may consider that the bigger safety margin should be applied to the frame of the lower rudder while no margin is applied to the shell plate (due to the membrane effects explained before).

As stated in paragraph 2, several combinations of intended downward speed $(0.05-0.5[\mathrm{~m} / \mathrm{s}])$ and trims $\left(1^{\circ}-3^{\circ}\right)$ have been considered. For all of them the stresses are calculated and taking into account the previous considerations an operational envelope can be drawn.

\begin{tabular}{c|ccccccc} 
Trim/speed & $\mathbf{0 . 0 5}$ & $\mathbf{0 . 1}$ & $\mathbf{0 . 1 5}$ & $\mathbf{0 . 2}$ & $\mathbf{0 . 2 5}$ & $\mathbf{0 . 3}$ & $\mathbf{0 . 5}$ \\
\hline $\mathbf{3}^{\mathbf{0}}$ & Yes & Yes & Yes & No & No & No & No \\
$\mathbf{2}^{\mathbf{0}}$ & Yes & Yes & Yes & No & No & No & No \\
$\mathbf{1}^{\mathbf{0}}$ & Yes & Yes & Yes & Yes & No & No & No
\end{tabular}

\section{Conclusions}

This report describes a wide range of subjects related to bottoming of the submarine. Hydrodynamics, soil mechanics and solid mechanics are treated in order to cover all aspects that may have influence on a safe operation.

It is emphasized that each aspect is subjected to limitations connected to the approach. Interaction between the hull and the surrounding water for example may be covered by more dedicated software. Soil mechanics must undoubtedly know more elaborated material models to cover the behaviour of the seabed. However the analysis results look realistic.

Questionable input, for instance seabed behaviour, will produce results on the same confidence level. Dedicated software will not be able to remove this 
uncertainty. The seabed is modelled as a homogeneous structure with stiffness based on sand. This input may be unrealistic, since the seabed will contain areas with more solid material, such as rocks. Nevertheless erroneous results in that case are induced by the input and the way of modelling or the software used will not be able to improve the result.

In other words, it will be interesting to compare the results presented here with the outcome of dedicated software. However there is no indication that the results given in this report are incorrect.

In summary, this type of simulation could help navies and submarine designers to define adequate operation envelop for bottoming operations. This of course should be done in combination with advanced tools for seabed classification [13].

\section{References}

[1] García Pelaez, J., Romero Valiente, G. and Reijmers, J.J., Bottoming of a submarine, Proc. Of the UDT 2012, Alicante.

[2] Blevins, R.D., Formulas for Natural Frequency and Mode shape, Van Nostrand Reinhold Company, New York, 1979.

[3] Soil mechanics, Polytechnisch zakboekje, edition 45, page F2/11.

[4] ANSYS ED, Release 10, LS-Dyna User's Guide, § 7.2.3.11 and § B.2.16.

[5] HSE, prepared by Liverpool University, Pulse pressure testing of $1 / 4$ scale blast wall panels with connections, Research report 124, 2003.

[6] Steel Construction Institute, Interim Guidance Notes for the design and protection of topside structures against explosion and fire, January 1992, SCI-P-112.

[7] Reijmers, J.J. The use of advanced material models in the analysis of plate collapse, NAFEMS World Congress 2007, Vancouver.

[8] Ship Grounding on Rock- I. Theory, Bo Cerup Simonson, Marine Structures 10, 1997, Page 519-562, Elsevier Science Limited.

[9] The Mechanics of Ship Collisions, Shengmin Zhang, 1999, Department of Naval Architecture and Offshore Engineering, Technical University of Denmark.

[10] S. Ehlers, J. Broekhuijsen, H. Alsos, F. Biehl and K. Tabri. Simulating the collision response of ship side structures: A failure criteria benchmark study. International Shipbuilding Progress 55. IOS Press.

[11] 17th International Ship and Offshore Structures Congress. Committee V.1, Damage Assessment after Accidental Events. August 2009.

[12] Rules for the Classification of Naval Submarines. Bureau Veritas. 2008 (draft).

[13] B Jalving, M Mandt, O K Hagen, F Pøhner. Terrain Referenced Navigation of AUVs and Submarines Using Multibeam Echo Sounders. Proc. UDT Europe 2004, Nice, France, June 2004. 